\title{
MICROSTRUCTURE AND NONSTOICHIOMETRY OF BARIUM STRONTIUM TITANATE THIN FILMS FOR DRAM APPLICATIONS*
}

S. Stemmer and N. D. Browning

Physics Dept.

Univ. of Illinois

Chicago, IL 60607-7059

\section{S. K. Streiffer}

Argonne National Laboratory

Materials Science Division

Argonne, IL 60439

\section{A. I. Kingon}

Department of Materials Science \& Engineering

North Carolina State University

Raleigh, NC 27695-7907

\section{April 1999}

The submitted manuscript has been
created by the University of Chicago as
Operator of Argonne National
Laboratory ("Argonne") under Contract
No. W-31-109-ENG-38 with the U.S.
Department of Energy. The U.S.
Government retains for itself, and others
acting on its behalf, a paid-up, non
exclusive, irrevocable worldwide license
in said article to reproduce, prepare
derivative works, distribute copies to the
public, and pertorm publicly and display
pu'blicly, by or on behalf of the
Government.

Government.

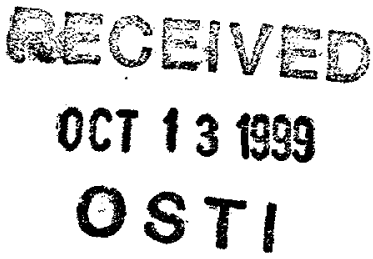

This paper was submitted to the Materials Research Society in San Francisco, CA, on April 5-9, 1999.

We wish to acknowledge support from the U.S. Department of Energy, BES-Materials Sciences, under Contract W-31-109-ENG-38 and DE-FG02-96ER45610, and by DARPA, contract \#8C392. 


\section{DISCLAIMER}

This report was prepared as an account of work sponsored by an agency of the United States Government. Neither the United States Government nor any agency thereof, nor any of their employees, make any warranty, express or implied, or assumes any legal liability or responsibility for the accuracy, completeness, or usefulness of any information, apparatus, product, or process disclosed, or represents that its use would not infringe privately owned rights. Reference herein to any specific commercial product, process, or service by trade name, trademark, manufacturer, or otherwise does not necessarily constitute or imply its endorsement, recommendation, or favoring by the United States Government or any agency thereof. The views and opinions of authors expressed herein do not necessarily state or reflect those of the United States Government or any agency thereof. 


\section{DISCLAIMER}

Portions of this document may be illegible in electronic image products. Images are produced from the best available original document. 


\title{
MICROSTRUCTURE AND NONSTOICHIOMETRY OF BARIUM STRONTIUM TITANATE THIN FILMS FOR DRAM APPLICATIONS
}

\author{
S. STEMMER*, S. K. STREIFFER **, N. D. BROWNING*, A. I. KINGON*** \\ *Department of Physics, University of Illinois at Chicago, Chicago, IL 60607-7059, \\ stemmer@uic.edu \\ **Argonne National Laboratory, Materials Science Division, Argonne, IL 60439-4838 \\ ***Department of Materials Science and Engineering, North Carolina State University, Raleigh, \\ NC 27695-7907
}

\section{ABSTRACT}

In this paper we investigate the microstructural accommodation of nonstoichiometry in $\left(\mathrm{Ba}_{\mathrm{x}} \mathrm{Sr}_{1-\mathrm{x}}\right) \mathrm{Ti}_{1+\mathrm{y}} \mathrm{O}_{3+\mathrm{z}}$ thin films grown by chemical vapor deposition. Films with three different $(\mathrm{Ba}+\mathrm{Sr}) / \mathrm{Ti}$ ratios of $49 / 51 \quad(y=0.04$ in the notation of the formula above), of 48/52 $(y=0.08)$ and of $46.5 / 53.5(y=0.15)$, were studied. High-resolution electron microscopy is used to study the microstructure of the BST films. High-spatial resolution electron energy-loss spectroscopy (EELS) is used to reveal changes in chemistry and local atomic environment both at grain boundaries and within grains as a function of titanium excess. We find an amorphous phase at the grain boundaries and grain boundary segregation of excess titanium in the samples with $y=0.15$. In addition, EELS is also used to show that excess titanium is being partially accommodated in the grain interior. Implications for the film electrical and dielectric properties are outlined.

\section{INTRODUCTION}

Thin films of $\left(\mathrm{Ba}_{\mathrm{x}} \mathrm{Sr}_{1-x}\right) \mathrm{Ti}_{1+y} \mathrm{O}_{3+z}$ (BST) are potential candidates as high permittivity dielectrics for very large scale integrated capacitor applications [1]. Therefore, many investigators have recently characterized the properties of these films, including dielectric response [2], leakage [3], and failure modes [4,5], as well as the dependence of these properties on composition, film thickness, temperature, etc.. It has been found that the $(\mathrm{Ba}+\mathrm{Sr}) / \mathrm{Ti}$ ratio $(y$ in the notation used above) strongly affects most film properties at a given ratio of $\mathrm{Ba} / \mathrm{Sr}$ (i.e. $x$ ) and deposition temperature $[6,7,8,9]$. Therefore, the $(\mathrm{Ba}+\mathrm{Sr}) / \mathrm{Ti}$ ratio is one of the primary parameters used to date to control the dielectric and electrical behavior of the films. BST films are routinely grown by chemical vapor deposition with severely nonstoichiometric $(\mathrm{Ba}+\mathrm{Sr}) / \mathrm{Ti}$ ratios, so as to achieve acceptable leakage currents and lifetime. For example, BST films with $x=0.7$ have a maximum resistance degradation lifetime at approximately $(\mathrm{Ba}+\mathrm{Sr}) / \mathrm{Ti}=48 / 52$ [4], corresponding to $y=0.083$, although the maximum value of the dielectric constant is found at $y=0$ [8]. Reasonable film behavior is generally achieved up to ratios of $46.5 / 53.5$ or $y=0.15$, which greatly exceeds the solubility of excess Ti in bulk BST, of approximately $y \leq 0.001$ [10]. Given this large nonstoichiometry, a necessary step in understanding the composition dependence of film properties is to determine the locations within the microstructure at which the excess titanium is accommodated in BST thin films. Here we report our measurements of this accommodation, as obtained using electron energy-loss spectroscopy in a transmission electron microscope operated in scanning mode (STEM).

\section{EXPERIMENTAL}

BST films were deposited to a thickness of $30 \mathrm{~nm}$ at approximately $640^{\circ} \mathrm{C}$ onto $100 \mathrm{~nm}$ thick, (111) fiber textured $\mathrm{Pt}$ films on $\mathrm{SiO}_{2} / \mathrm{Si}$ wafers by a high-composition-precision, liquid 
delivery source chemical vapor deposition technique, described in Ref. 8. Film composition and thickness were determined by a x-ray fluorescence technique also described in Ref. 8 . The Ba content was fixed at $x=0.7$. Samples of three different (Ba+Sr)/Ti ratios, 49/51 $(y=0.04)$, of 48/52 $(y=0.08)$, and $46.5 / 53.5(y=0.15)$, were investigated. X-ray diffraction revealed the films to be almost purely $\{100\}$ textured. The BST grains in both samples were found to have typical lateral dimensions of $10-20 \mathrm{~nm}$, and are known to be columnar from previous work [4, 9]. TEM samples were prepared by removing the $\mathrm{Pt} / \mathrm{BST}$ heterostructure from the $\mathrm{SiO}_{2} / \mathrm{Si}$ substrate followed by ion-milling of the Pt. The film microstructure and chemistry were investigated using a $200 \mathrm{kV}$ transmission electron microscope (JEOL JEM 2010F) equipped with a field-emission gun, an annular dark-field detector and a post-column imaging filter (Gatan GIF200). This microscope is capable of achieving a probe size of $0.14 \mathrm{~nm}$ in STEM, for microanalysis and incoherent Z-contrast lattice imaging [11]. The smallest probe size used in this study was about $0.2 \mathrm{~nm}$. Conventional high-resolution imaging was used for detecting amorphous phases at grain boundaries. EELS was used for studying relative composition and bonding changes in BST grain interiors versus at grain boundaries, as well as for investigating differences between the three samples.

For EELS, the microscope was operated in scanning mode. In STEM, a lattice resolution Z-contrast image was acquired on the GIF annular dark field detector. Resolution of the BST lattice planes in this image confirmed a probe size of no more than $0.4 \mathrm{~nm}$; more importantly, the Z-contrast image was used to position the probe precisely at the region of interest, e.g. the grain interior or the grain boundary plane. The EELS spectrum could then be acquired immediately without changing the optical parameters of the microscope, a technique that has to this point been applied only in dedicated STEMs [12]. EELS of Ti $\mathrm{L}_{2,3}$ and O K-edges were recorded in each sample by positioning the probe on a number of grain boundaries and in the center of the respective adjacent grains. After appropriate background subtraction, relative compositions (e.g., $\mathrm{Ti} / \mathrm{O}$ ratios) were extracted at each location by integrating the respective edges from a given location over an energy window and obtaining an edge count ratio. In separate measurements, near edge fine structure (ELNES), which is sensitive to changes in bonding and local atomic environment, was studied by recording $\mathrm{Ti} \mathrm{L}_{2,3}$ and $\mathrm{O} \mathrm{K}$-edges on and off the grain boundaries, using a larger energy dispersion. The energy resolution at the zero-loss peak under these conditions was about $1.2 \mathrm{eV}$ [full width at half maximum (FWHM)].

\section{RESULTS}

Figure 1 shows a high-resolution TEM plan-view micrograph of the film with $y=0.08$. Occasionally, amorphous areas are observed in this sample and in the sample with $y=0.15$ in

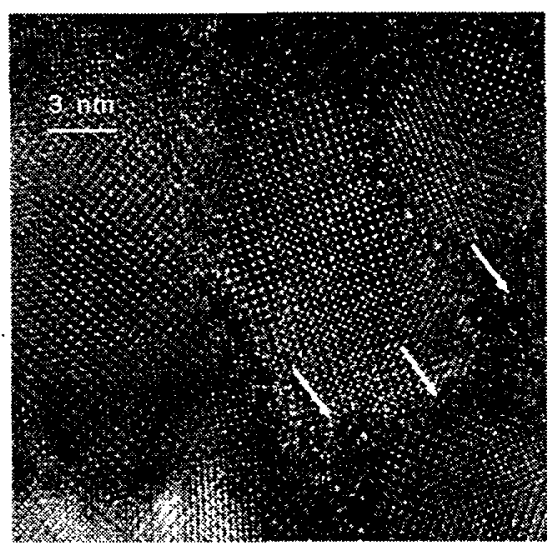
triple pockets and along grain boundaries, as indicated by arrows in Figure 1. This is consistent with the observations of others on similar samples [13]. In contrast, the sample with $y=0.04$ contained no detectable amorphous phase. Figure 2 shows a cross-section HRTEM image of the sample with $y=0.15$ recorded at the interface between the $\mathrm{Pt}$ electrode and the BST film. No secondary phases are detectable at the interface.

Figure 1: HRTEM plan-view micrograph of the sample with $y=0.08$. The grains are oriented close to $<100\rangle$. Arrows indicate the presence of amorphous phase. 


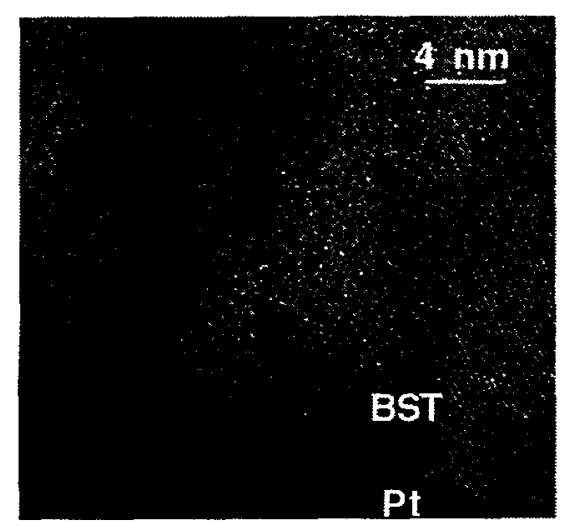

Figure 2: HRTEM crosssectional micrograph of the BST $(y=0.15) \quad$ film/ Pt-electrode interface.

In a previous paper we have shown that $\mathrm{Ti}$ segregates to the grain boundaries in BST films with $y=0.15$ [14]. Figure 3 summarizes the results. For the $y=0.04$ sample (Figure $3(\mathrm{a})$ ), no increase in the $\mathrm{Ti} / \mathrm{O}$ ratio at the grain boundaries compared to the grain interior can be detected within the resolution of the measurement. In strong contrast, the $y=0.15$ sample (Figure $3(\mathrm{c})$ ) shows a very significant increase of the $\mathrm{Ti} / \mathrm{O}$ ratio at most grain boundaries, indicating a segregation of excess titanium to the grain boundaries in this sample. The Ti/O ratios for the $y=0.08$ sample (Figure $3(b)$ ) show a slight increase in $\mathrm{Ti} / \mathrm{O}$ ratio at the grain boundaries.

Figure 4 shows the fine structure of the oxygen $\mathrm{K}$ edges in two samples, recorded on and off the grain boundaries. In the $y=0.04$ sample (Figure 4 (a)), no differences in the fine structure between the spectra recorded on and off the grain boundaries can be detected within the limit of the method. However, in the $y=0.15$ sample (Figure $4(b)$ ), the fine structure of the spectra recorded on the grain boundaries is significantly different from that found in the grain interior. The most significant change occurs in the peak denoted " $b$ " in Figure 4, which is reduced in intensity in the spectra recorded on the grain boundaries. For comparison purposes, Figure 4 (c) shows reference spectra of the oxygen K-edges obtained from bulk ceramics of rutile $\mathrm{TiO}_{2}$ and $\mathrm{SrTiO}_{3}[15,16]$, respectively. Given our energy resolution, the principal features of the oxygen K-edge in BST are the same as those in $\mathrm{SrTiO}_{3}$, as can be seen from the respective oxygen K-edges in the work of Brydson, et al. [17]. The spectra can be interpreted as follows. Peak $a$ and $a_{2}$ (cf. SrTiO3 reference spectrum) represent the coordination to the Ti nearest neighbors $[16,18]$ whereas peak $b$ is sensitive to the first nearest oxygen neighbors [16].
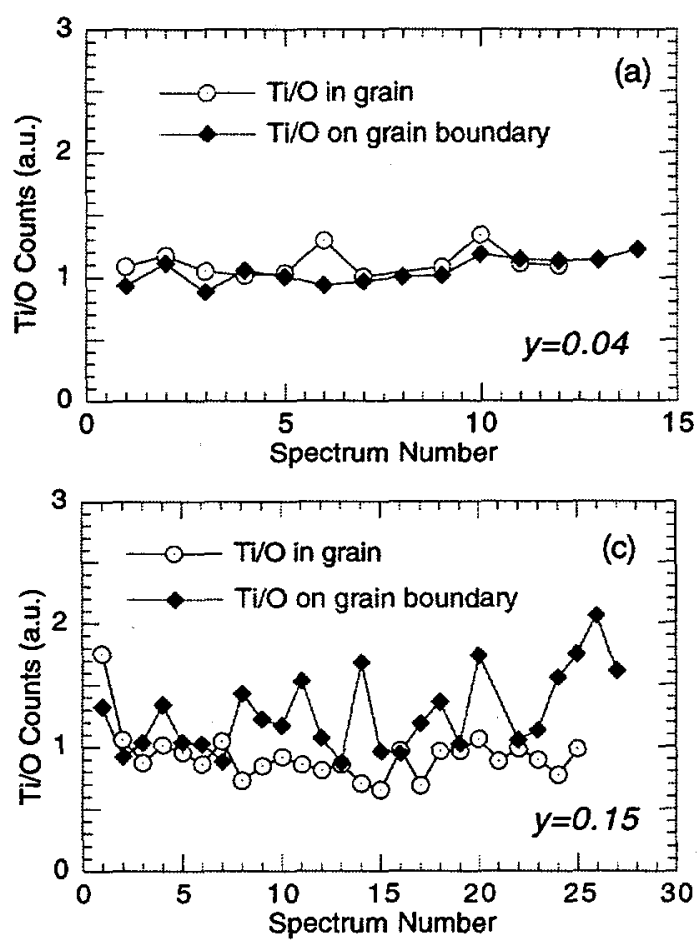

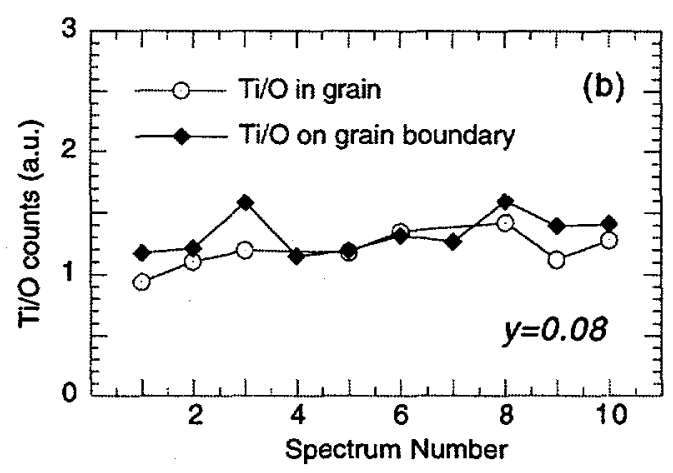

Figure 3: Integrated $\mathrm{Ti} / \mathrm{O}$ edge count ratios (obtained by integration over the $\mathrm{Ti} \mathrm{L}_{2,3}$ and $\mathrm{O} \mathrm{K}$-edge, respectively) at grain boundaries (diamonds) and in the grain interior (circles) for (a) the $y=0.04$ sample, (b) the $y=0.08$ sample, and (c) the $y=0.15$ sample. 

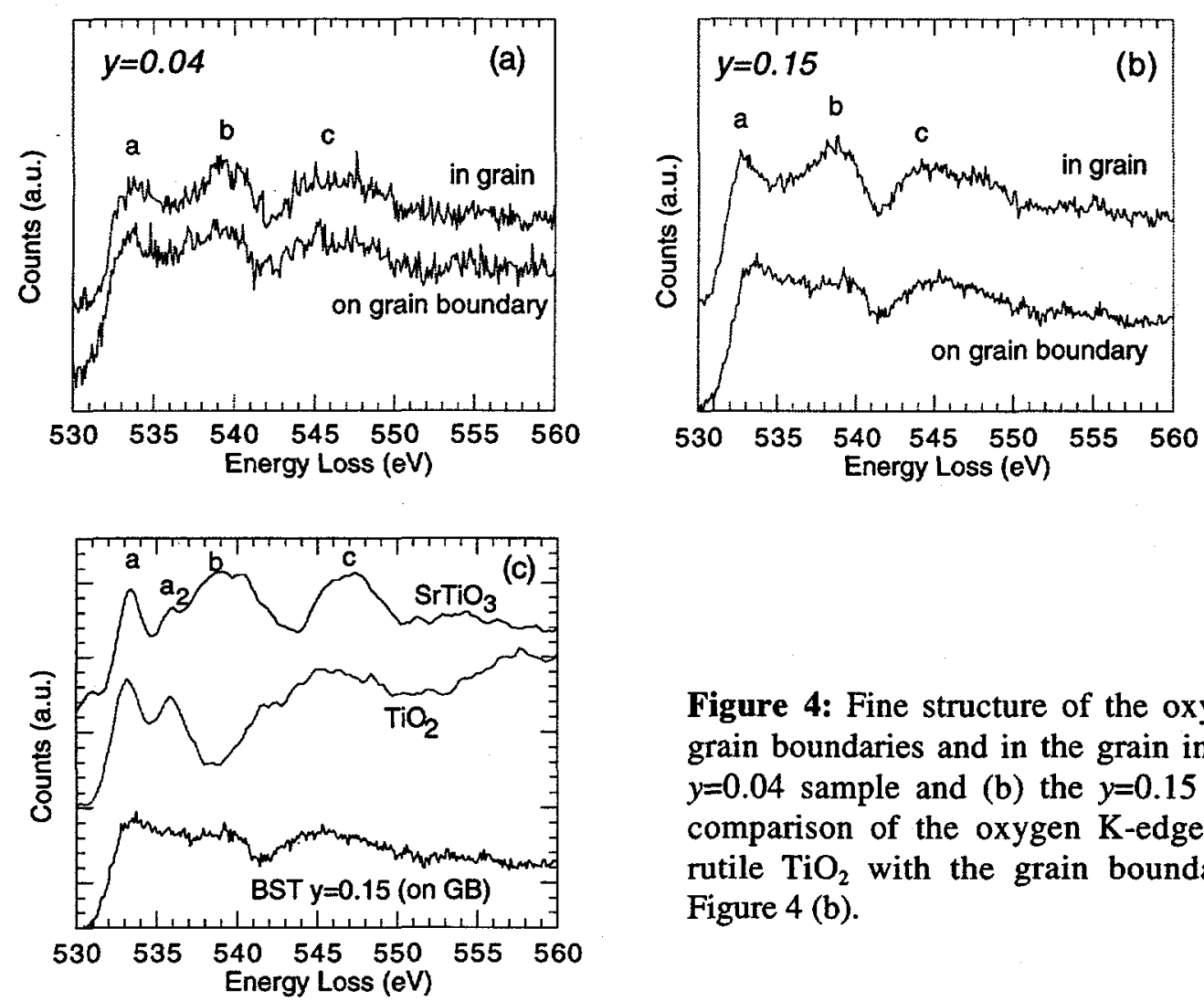

Figure 4: Fine structure of the oxygen K-edges on grain boundaries and in the grain interior for (a) the $y=0.04$ sample and (b) the $y=0.15$ sample, (c) is a comparison of the oxygen $\mathrm{K}$-edges in $\mathrm{SrTiO}_{3}$ and rutile $\mathrm{TiO}_{2}$ with the grain boundary spectrum of Figure 4 (b).

The crystal field splitting resulting in peak $a$ and $a_{2}$ is not very well resolved in our spectra due to the insufficient signal to noise ratio. A change in the intensity of peak $a$ relative to peak $a_{2}$ has been found to be a general feature of grain boundaries in $\mathrm{SrTiO}_{3}$, and is due to the distortion of the linear Ti-O bond within the grain boundary [16]. It is therefore a feature independent of the segregation of titanium to the grain boundaries. With respect to the segregation of $\mathrm{Ti}$, the important change in the ELNES is the observed drastically reduced intensity of peak " $b$ " in the spectra recorded on the grain boundaries in BST films with $y=0.15$. In rutile, the peak corresponding to the peak $b$ in the $\mathrm{SrTiO}_{3}$ spectrum is shifted to higher energy losses (it occurs there at approximately the same energy loss as the peak denoted "c" in $\mathrm{SrTiO}_{3}$ ). The reduced intensity of peak $b$ in the grain boundaries in BST films with $y=0.15$ can be interpreted as the combined presence of ELNES features characteristic of both $\mathrm{TiO}_{2}$ and BST (cf. Figure 4(c)).

Our result of an increased $\mathrm{Ti} / \mathrm{O}$ ratio at the grain boundaries of the $y=0.15$ sample clearly shows that excess titanium in nanocrystalline BST films is accommodated at the grain boundaries, when the amount of $\mathrm{Ti}$ is very high. This is also supported by our observation that the fine structure of the oxygen edge recorded on the grain boundaries in this sample resembles features of rutile. Furthermore, at this overall composition some excess Ti appears to segregate out as an amorphous phase in triple pockets and occasionally at grain boundaries as $\mathrm{TiO}_{\mathrm{x}}$. The appearance of this amorphous material at Ti contents greater than $y=0.083$ could explain the nonmonotonic behavior of properties such as resistance degradation, as Ti content is increased. However, a more detailed interpretation of electrical properties is beyond the scope of this first report. 

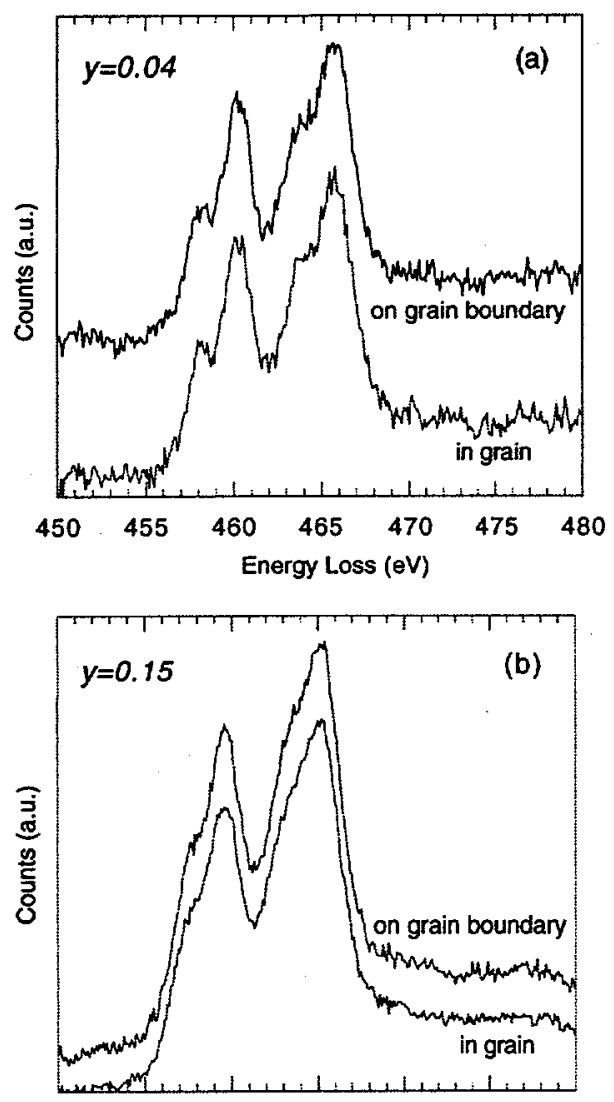

Figure 5: Fine structure of the titanium $\mathrm{L}_{2,3}$-edges on grain boundaries and in the grain interior for (a) the $y=0.04$ sample, and (b) the $y=0.15$ sample.

More significantly, our investigations provide evidence that some portion of the excess titanium in these very highly nonstoichiometric samples may be accommodated within the grain interiors. Figure 5 shows the $\mathrm{Ti}_{2,3}$ edges in the two samples, on and off the grain boundaries. In neither of the two films can a pronounced difference in the ELNES between the spectra recorded on and off the grain boundaries be observed within the detection limit of the method. However, differences in the spectra between the two samples are observed. The $\mathrm{L}_{2,3}$-edges in the $y=0.15$ sample (Figure 5(b)) are slightly broadened compared to those of the $y=0.04$ sample (Figure 5 (a)). This causes the splitting of the $L_{2}$ and $L_{3}$ edges, which is attributed to the crystal field splitting of the $t_{2 g}$ and $e_{g}$ orbitals, to appear less pronounced in the $y=0.15$ sample relative to the $y=0.04 \mathrm{BST}$ film.

The ELNES of the $\mathrm{L}_{2,3}$-edge of titanium in perovskites and $\mathrm{TiO}_{2}$ has generally been found to reflect the nearest-neighbor environment $[19,20]$. In this case this indicates that the octahedral coordination of titanium is maintained in both samples in the grains and on the grain boundaries. However, broadening of the Ti $L_{2,3}$ ELNES features implies that these octahedra are increasingly distorted as the titanium content increases, because broadening can be attributed to a loss in symmetry or a distortion of the bonds [17, 21].

Accommodation of excess titanium in the grain interior is the most likely reason for this distortion, as this is the only significant difference in microstructure between the two samples. The atomistic defect mechanisms by which the incorporation of excess titanium occurs in the grains is still an open question, as is the specific relationship to electrical behavior.

It should be noted that it has previously been observed that the near edge fine structure of Ti L-edges in $\mathrm{SrTiO}_{3}$ and $\mathrm{BaTiO}_{3}$ do not change on grain boundaries [16, 22]. It appears to be a general feature in these materials that $\mathrm{Ti}$ maintains its octahedral coordination at grain boundaries, even in cases where Ti is thought to segregate to the boundaries [23]. Within our energy resolution we also do not expect to observe a change in $\mathrm{Ti}$ L-edge fine structure due to the presence of $\mathrm{TiO}_{2}$ at the grain boundaries, as $\mathrm{Ti}$ is octahedrally coordinated in $\mathrm{TiO}_{2}$. In contrast to this, the oxygen $\mathrm{K}$-edge is sensitive to long-range distortions [16, 17].

In summary, we have reported the microstructural accommodation of excess titanium in polycrystalline $\left(\mathrm{Ba}_{x} \mathrm{Sr}_{1-\mathrm{x}}\right) \mathrm{Ti}_{1+y} \mathrm{O}_{3+\mathrm{z}}$ films. We have observed partial accommodation of titanium in the grain interiors, either concurrent with or followed by accommodation at the grain boundaries. At extreme titanium excess, an amorphous phase, possibly $\mathrm{TiO}_{x}$, can be found between grains. The increased grain boundary area in these nanocrystalline films, compared with that in much larger grained bulk ceramics, in combination with the non-equilibrated microstructure of our films due to relatively low processing temperature, may explain why Ti contents well beyond the bulk solid solubility limit are tolerated by the structure. 
We acknowledge funding by the U.S. Department of Energy, Basic Energy Sciences Materials Science through contract no. DE-FG02-96ER45610 and contract \#W-31-109-ENG-38, and by DARPA, contract \# 8C392. BST samples were provided by Advanced Technology Materials, Inc., through the DARPA Ultradense Capacitor Materials Processing Partnership, NCSU contract ATM93-734-05.

\section{References}

1. See A. I. Kingon, S. K. Streiffer, C. Basceri, and S. R. Summerfelt, MRS Bull. 21, 46 (1996), and references therein.

2. C. Basceri, S. K. Streiffer, A. I. Kingon, R. Waser, J. Appl. Phys. 82, 2497 (1997).

3. See G. W. Dietz, M. Schumacher, R. Waser, S. K. Streiffer, C. Basceri, A. I. Kingon, J. Appl. Phys. 82, 2359 (1997), and references therein. S. Zafar, R.E. Jones, Bo Jiang, B. White, P. Chu, D. Taylor, and S. Gillespie, Appl. Phys. Lett. 73, 175 (1998). Y. Fukuda, K. Numata, K. Aoki, A. Nishimura, G. Fujihashi, S. Okamura, S. Ando, and T. Tsukamoto, Jap. J. Appl. Phys. Part 2 (Letters) 37, L453 (1998).

4. C. Basceri, S.E. Lash, C.B. Parker, S.K. Streiffer, A.I. Kingon, M. Grossmann, S. Hoffmann, M. Schumacher, R. Waser, S. Bilodeau, R. Carl, P.C. van Buskirk, and S.R. Summerfelt, in Ferroelectric Thin Films VI, MRS Symp. Proc. 493 edited by R.E. Treece, R.E. Jones, C.M. Foster, S.B. Desu, and I.K. Yoo, (MRS, Warrendale, PA, 1998), pp. 9-14.

5. K. Numata, Y. Fukuda, K. Aoki, and A. Nishimura, Jap. J. Appl. Phys. Part 1 34, 5245 (1995).

6. S. Yamamichi, H. Yabuta, T. Sakuma, Y. Miyasaka, Appl. Phys. Lett. 64, 1644 (1994).

7. T. Kawahara, M.Yamamuka, T. Makita, J. Naka, A. Yuuki, N. Mikami, K. Ono, Jpn. J. Appl. Phys. 33, 5129 (1994).

8. P. C. van Buskirk, J. F. Roeder, S. Bilodeau, Integr. Ferroelectr. 10, 9 (1995). S.M. Bilodeau, R. Carl, P.C. Van Buskirk, J.F. Roeder, C. Basceri, S.E. Lash, C.B. Parker, S.K. Streiffer, and A.I. Kingon, J. Korean Phys. Soc. 32, S1591 (1998).

9. C. Basceri, Ph.D. Dissertation, North Carolina State University (1997).

10. R.K. Sharma, N.-H. Chan, and D.M. Smyth, J. Am. Ceram. Soc. 64, 448 (1981). S. Witek, D.M. Smyth, and H. Pickup, J. Am. Ceram. Soc. 67, 372 (1984).

11. E. M. James, N. D. Browning, Ultramicroscopy, in press. (1999).

12. N. D. Browning, M. F. Chisholm, S. J. Pennycook, Nature 366, 143 (1993).

13. I. Levin, R.D. Leapman, D. L. Kaiser, to be published.

14. S. Stemmer, S. K. Streiffer, N. D. Browning, A. I. Kingon, Applied Physics Letters, in press.

15. D. J. Wallis, N. D. Browning, J. Am. Ceram. Soc. 80, 781 (1997).

16. N. D. Browning, H. O. Moltaji, J. P. Buban, Phys. Rev. B 58, 8289 (1998).

17. R. Brydson, H. Sauer, W. Engel, F. Hofer, J. Phys.: Condens. Matter 4, 3429 (1992).

18. F. M. F. de Groot, J. Faber, J. J. M. Michiels, M. T. Czyzyk, M. Abbate, J. C. Fuggle, Phys. Rev. B 48, 2074 (1982).

19. R. Brydson, H. Sauer, W. Engel, J. M. Thomas, E. Zeitler, N. Kosugi, H. Kuroda, J. Phys.: Condens. Matter 1, 797 (1989).

20. N. D. Browning, S. J. Pennycook, J. Phys. D: Appl. Phys. 29, 1779 (1996).

21. F. M. F. de Groot, J. Electron Spectrosc. 67, 529 (1994).

22. A. Recnik, J. Bruley, W. Mader, D. Kolar, M. Rühle, Philos. Mag. B 70, 1021 (1994).

23. Y-M. Chiang. T. Takagi, J. Am. Ceram. Soc. 73, 3278 (1990). 